\title{
Acute right ventricular failure after pediatric cardiac transplant: Predictors and long-term outcome in current era of transplantation medicine
}

\author{
Aparna Hoskote, MD, MRCP, ${ }^{\mathrm{a}}$ Catherine Carter, MSc, MPH, RN, ${ }^{\mathrm{b}}$ Phillip Rees, MB, FRCP, ${ }^{\mathrm{b}}$ \\ Martin Elliott, MD, FRCS, ${ }^{\mathrm{c}}$ Michael Burch, MD, FRCP, FRCPCH, ${ }^{\mathrm{b}}$ and Katherine Brown, MPH, MRCP ${ }^{\mathrm{a}}$
}

Objectives: To identify pretransplant factors associated with postprocedural right ventricular failure and the relationship between right ventricular failure and long-term survival in children.

\begin{abstract}
Methods: Records were reviewed for children having heart transplantation from 2000 to 2006.
Results: Right ventricular failure was identified by clinical and echocardiographic parameters in 33/129 (25\%) recipients: dilated cardiomyopathy in 14/90 (15\%), congenital heart disease in 11/27 (41\%), and restrictive cardiomyopathy in 8/12 (66\%). In 9 of $12(75 \%)$, known elevated (reactive) pulmonary vascular resistance progressed to right ventricular failure. In a further 23/117 (20\%) recipients, pulmonary vascular resistance within predefined acceptable range progressed to right ventricular failure. Multiple logistic regression analyses indicated elevated pulmonary vascular resistance (odds ratio $12.30 ; 95 \%$ confidence interval $2.73,55.32 ; P=.001$ ) and primary diagnosis, restrictive cardiomyopathy (odds ratio 9.21; 95\% confidence interval 2.07, 41.12; $P=.004$ ), and congenital heart disease (odds ratio 4.07; 95\% confidence interval 1.36, 12.19; $P=.012$ ) were strongly associated with right ventricular failure, but duration of heart failure, pretransplant mechanical support, donor status, and ischemic times were not. Treatment included inhaled nitric oxide in $28(84 \%)$, mechanical support in $10(31 \%)$, hemofiltration in $13(40 \%)$, and retransplantation in 2. A Cox multiple regression model including: primary diagnosis, right ventricular failure, and elevated pulmonary vascular resistance indicated that only the latter was independently linked with eventual mortality (hazards ratio $5.45 ; 95 \%$ confidence interval $1.36,21.96 ; P=.017)$.
\end{abstract}

Conclusions: Primary diagnosis and pretransplant elevated reactive pulmonary vascular resistance are both linked to the evolution of right ventricular failure. Pulmonary vascular resistance assessment in end-stage heart failure is challenging; therefore, avoidance of right ventricular failure may not always be possible. Aggressive early treatment may mitigate the effects of right ventricular failure: pretransplant elevated pulmonary vascular resistance was independently associated with long-term survival, but right ventricular failure was not. (J Thorac Cardiovasc Surg 2010;139:146-53.)

Early transplant literature has suggested that preoperative pulmonary hypertension with increased pulmonary vascular resistance (PVR) is a risk factor not only for early death ${ }^{1-4}$ but also for perioperative morbidity such as posttransplant infections and arrhythmias. ${ }^{5}$ Recently, significant advances have been made in pediatric heart transplantation with much improved overall outcomes, ${ }^{6-9}$ but recipient selection remains a key factor in determining successful outcome. Despite advances in perioperative management and careful preselection, right ventricular failure (RVF) still occurs in pediatric recipients, ${ }^{10-12}$ but the predictors and outcome of

From the Cardiac Critical Care Unit, ${ }^{\mathrm{a}}$ Cardiothoracic Transplant Medicine, ${ }^{\mathrm{b}}$ and Cardiothoracic Surgery, ${ }^{\mathrm{c}}$ Great Ormond Street Hospital for Children NHS Trust, London, United Kingdom.

Received for publication Dec 23, 2008; revisions received July 3, 2009; accepted for publication Aug 10, 2009; available ahead of print Nov 12, 2009.

Address for reprints: Aparna Hoskote, MD, MRCP, Consultant in Cardiac Critical Care, Cardiac Critical Care Unit, Great Ormond Street Hospital for Children NHS Trust, Great Ormond Street, London WC1N 1JH, United Kingdom (E-mail: hoskoa@gosh.nhs.uk).

0022-5223/\$36.00

Copyright (c) 2010 by The American Association for Thoracic Surgery doi: $10.1016 /$ j.jtcvs. 2009.08 .020
RVF in the current era of pediatric transplantation are not well described. Registry data from the International Society of Heart and Lung Transplantation reveal that RVF accounts for $50 \%$ of all cardiac complications and $19 \%$ of early deaths in adult patients in the posttransplant period. ${ }^{13}$ As in adults, threshold hemodynamic values to predict RVF are not entirely reliable in children. ${ }^{1}$ Long-standing endstage heart disease, regardless of etiology, can cause progressively increasing pulmonary venous hypertension. ${ }^{14,15}$ Raised PVR is frequently documented in patients with long-standing restrictive cardiomyopathy $(\mathrm{RCM})^{16-18}$ as well as in patients with failing single-ventricle palliation, ${ }^{19}$ and increasing numbers of patients with palliated single ventricle are being listed for transplantation. ${ }^{20,21}$ In addition, preoperative assessment of PVR by cardiac catheterization may not always yield adequate or reliable information, especially when hemodynamically tested in a low cardiac output state. ${ }^{19,22}$ It is also speculated that prolonged graft ischemic times with suboptimal right heart protection may potentially be associated with RVF in the immediate postoperative period. 

Abbreviations and Acronyms
BSA = body surface area
CHD = congenital heart disease
$\mathrm{DCM}=$ dilated cardiomyopathy
$\mathrm{ECMO}=$ extracorporeal membrane oxygenation
iNO = inhaled nitric oxide
PVR = pulmonary vascular resistance
PVRI = pulmonary vascular resistance index
$\mathrm{RCM}=$ restrictive cardiomyopathy
$\mathrm{RVF}=$ right ventricular failure
$\mathrm{TPG}=$ transpulmonary gradient

We performed a single-center, retrospective analysis of all patients with orthotopic heart transplantation over a period of 7 years and identified those with acute RVF in the immediate postoperative period. In particular, we aimed to identify factors linked with the evolution of RVF and to study the subsequent relationship between RVF and long-term outcome.

\section{METHODS}

The study was registered with and approved by the Research and Development Office at the Institute of Child Health, London. All heart transplant recipients within the study time frame were included, and a subgroup with acute RVF was identified. The diagnosis of RVF was a "clinical syndrome", based on a constellation of clinical "bedside" and echocardiographic signs. These were: elevated central venous pressure and raised pulmonary artery pressures more than two-thirds systemic arterial pressure on invasive monitoring; clinical picture of a low cardiac output state; and supportive echocardiographic features including poor systolic function of the right ventricle with significant tricuspid regurgitation and raised estimated right ventricle systolic pressure in the context of preserved left ventricular ejection. The pulmonary artery pressures were not used in isolation, as a failing right ventricle may not be able to generate higher pressures. Patients with acute graft failure with predominant left ventricular failure or biventricular failure were excluded from the definition of RVF.

The following data were collected.

1. Preoperative variables: primary cardiac diagnoses of (a) dilated cardiomyopathy (DCM), (b) RCM, and (c) congenital heart disease (CHD); duration of end-stage heart failure from diagnosis to transplantation; presence of increased PVR (defined below); age; weight and requirement for pretransplant ventilation and/or mechanical support.

2. Intraoperative variables: graft ischemic time, donor/recipient age weight and body surface area (BSA) mismatch, donor cause of death, and marginal donor status (defined below).

3. Postoperative status: duration of ventilation, use of inhaled nitric oxide (iNO), right ventricular assist device, and extracorporeal membrane oxygenation (ECMO), length of intensive care stay, and subsequent survival status up to the end of January 2008.

\section{Pretransplant PVR}

Acceptable institutional listing criteria for heart transplant for preoperative PVR were defined as PVR index (PVRI) $\leq 6 \mathrm{WU} \cdot \mathrm{m}^{2}$ and/ or a transpulmonary gradient (TPG) $\leq 15 \mathrm{~mm} \mathrm{Hg}$ and mean pulmonary artery pressure $<25 \mathrm{~mm} \mathrm{Hg}$. The catheter data were reviewed to assess reversibility of PVR in different situations with $1.0 \mathrm{FIO}_{2}$ and iNO. Echocardio- graphic parameters in the absence of catheter data for identification of preoperative PVR were defined (as per convention) primarily on the basis of raised (two-thirds of systemic systolic pressure and above) estimated right ventricular systolic pressure (RVSP) calculated from the tricuspid regurgitant jet peak systolic gradient and other supporting data specific to the underlying diagnosis. A group with elevated PVR was then identified from patients who had pulmonary hemodynamic data outside these defined acceptable values but in all, there was evidence of pulmonary vascular reactivity on hemodynamic testing.

\section{Marginal Donor Status}

Marginal donor statues was defined in our institution as follows: donor age $>40$ years, size mismatch of $>3$ times weight, high inotropic need, cardiac arrest in the donor, and a history of donor smoking or drug abuse.

\section{Data Analysis}

Comparison between the 2 groups (patients with and without RVF) was performed using Wilcoxon rank sum test for continuous and a chi-square test for categorical variables. Continuous variables are expressed as median with interquartile range (IQR). Univariate logistic regression analysis was performed to assess the relationship between variables of interest and RVF. Risk factors that appeared statistically related to the occurrence of RVF were further investigated using multiple logistic regression models. Long-term outcome of recipients was evaluated with a Cox proportional hazards model, considering the importance of potential risk factors for death over time. Again, factors that appeared to be statistically related to outcome on univariate analysis were further investigated using a Cox multiple regression models.

\section{RESULTS}

Over this 7-year period, a total of 129 children had orthotopic heart transplantation. The primary diagnosis was DCM in $90(70 \%)$, CHD in $27(21 \%)$, and RCM in $12(9 \%)$. The median age at transplantation was 9.5 (IQR $2.8,13.6)$ years.

\section{Patients With Acute RVF}

Of 129 recipients, acute posttransplant RVF developed in $33 / 129(25 \%)$ as identified by clinical, hemodynamic, and echocardiographic parameters. In 14 of 33, RVF was identified immediately after coming off bypass; RVF developed in a further 15 within 24 hours; and in the remaining 4, between 24 and 48 hours. The median highest central venous pressure in those with RVF was 20 (IQR 16, 22), and the median left atrial pressure was 10 (IQR 8, 11).

\section{Comparison With the Non-RVF Group}

Primary diagnosis. RVF was significantly linked to the primary diagnosis $(P<.001)$ and was most prevalent in RCM 8/12 (66\%), then CHD 11/27 (41\%), and least common in DCM 14/90 (15\%; Table 1). Of the $11 \mathrm{RVF}$ patients with CHD, 7 (64\%) were transplanted following functional single-ventricle palliation ( 3 after bidirectional cavopulmonary anastomosis, 3 after total cavopulmonary anastomosis, 1 after Kawashima surgery), and 4 were transplanted following biventricular repair. There was no difference in the 
TABLE 1. Patient characteristics: Diagnosis, preoperative and operative variables in those with and without RVF

\begin{tabular}{|c|c|c|c|}
\hline Characteristics & $\begin{array}{c}\text { RVF } \\
(\mathbf{n}=33)\end{array}$ & $\begin{array}{l}\text { No RVF } \\
(n=96)\end{array}$ & $\begin{array}{c}P \\
\text { value }\end{array}$ \\
\hline Age (y) & $6.7(2.6,13.1)$ & $10.8(2.9,13.7)$ & .50 \\
\hline Diagnosis & & & $<.0001$ \\
\hline $\operatorname{DCM}(\mathrm{n}=90)$ & $14(15 \%)$ & $76(85 \%)$ & \\
\hline $\operatorname{RCM}(\mathrm{n}=12)$ & $8(66 \%)$ & $4(33 \%)$ & \\
\hline $\mathrm{CHD}(\mathrm{n}=27)$ & $11(41 \%)$ & $16(59 \%)$ & \\
\hline Duration of heart failure (d) & $420(147,571)$ & $169(83,375)$ & .03 \\
\hline Elevated PVR & $9(27 \%)$ & $3(3 \%)$ & $<.001$ \\
\hline Ischemic time (min) & $236(200,280)$ & $223(190,254)$ & .21 \\
\hline Donor to recipient age ratio & $2.17(1.30,2.50)$ & $1.75(1.20,2.90)$ & .47 \\
\hline Donor to recipient weight ratio & $1.7(1.4,2.3)$ & $1.6(1.2,2.0)$ & .77 \\
\hline Donor to recipient BSA ratio & $1.48(1.24,1.71)$ & $1.33(1.11,1.62)$ & .07 \\
\hline Marginal donor & $11(33 \%)$ & $40(41 \%)$ & .40 \\
\hline $\begin{array}{l}\text { Pretransplant mechanical } \\
\text { support }\end{array}$ & $7(21 \%)$ & $20(21 \%)$ & .96 \\
\hline Days ventilated & $11.2(3.7,18)$ & $3.3(1.2,11.6)$ & .003 \\
\hline Days in intensive care & $12.8(7.0,22)$ & $6.6(3.2,16)$ & .006 \\
\hline
\end{tabular}

Results are median (interquartile range) or $\mathrm{n}(\%)$. All medians compared with Wilcoxon rank sum test and proportions by chi-square test. $B S A$, Body surface area; $C H D$, congenital heart disease; $D C M$, dilated cardiomyopathy; $P V R$, pulmonary vascular resistance; $R C M$, restrictive cardiomyopathy; $R V F$, right ventricular failure.

proportion of patients transplanted after single-ventricle palliation between the 2 groups.

Duration of heart failure from diagnosis to transplantation. The median duration of end-stage heart failure from diagnosis to transplantation in the RVF group was significantly longer at 420 (IQR 147, 571) days, compared with the non-RVF group: 169 (IQR 83, 375) days $(P=.03)$.

Pretransplant PVR. The majority of patients with elevated PVR 9/12 (75\%) developed RVF $(P<.001)$; the PVR group is described below. However, 24/33 (72\%) children with RVF did not have recognized signs of raised PVR, as measured by echocardiography in 14 (median calculated RVSP $36 \mathrm{~mm} \mathrm{Hg}$; IQR 36, 40) and by cardiac catheterization in 10 (median TPG $8 \mathrm{~mm} \mathrm{Hg}$;QR 8, 9). Of the 14 who did not have catheter examination, 10 had DCM, 4 had CHD, and 5 were bridged on ECMO to transplant. All had severe end-stage heart failure with median left ventricular shortening fraction of $10 \%$ (IQR 9, 14).

Pretransplant mechanical support. Of all included patients, 27/129 (21\%) were bridged to transplant on mechanical support; this proportion was similar between the RVF and non-RVF groups $(P=.96)$.

Intraoperative variables. The median graft ischemic time was 236 (IQR 200, 280) minutes in those with RVF, and this was not statistically different in the non-RVF group $(P=.95)$. There was no significant difference in either the donor to recipient weight ratio $(P=.77)$ or the donor to recipient age ratio $(P=.47)$. There was some suggestion that an increased donor to recipient BSA ratio may have been linked to $\operatorname{RVF}(P=.07)$, but this was not statistically significant. Based on our institutional criteria, there was no evidence that the percentage receiving a marginal donor organ differed between the RVF and non-RVF groups $(P=.40)$. The 3 major causes of donor death were trauma in $53(41 \%)$, intracranial hemorrhage in $43(33 \%)$, and hypoxia in $11(9 \%)$, of which 2 were due to smoke inhalation; there was no statistical relationship between donor cause of death and $\mathrm{RVF}(P=.16)$.

\section{The Elevated PVR Group}

Pretransplant PVR was diagnosed on the basis of catheter data for those with RCM, on the basis of echocardiographic data in those with DCM except in 7 (for whom catheter data were available), and on the basis of echocardiographic and catheter data for the CHD group. A small group of 12/129 (9\%) patients had elevated pretransplant PVR. The median TPG in those who were catheterized $(\mathrm{n}=9)$ was $16(\mathrm{IQR} 15$, 19), mean pulmonary artery pressure was 40 (IQR 38, 42), and the estimated median RVSP in those who did not have cardiac catheterization was 64 (IQR 64, 66) $\mathrm{mm} \mathrm{Hg}$. Four (3 with RCM and 1 with DCM) had preoperative vasodilator treatment with prostacyclin with some reduction in either TPG or PVRI. All had some reversibility of PVR and were considered acceptable for listing for heart transplantation with the option of right ventricular assist device to be initiated in the operating room in the event of deterioration. There were 3 patients in whom, despite concerns for borderline elevated PVR, there was no clinical syndrome of acute RVF, though all had prolonged intensive care stay. We found no evidence that children with elevated PVR were given better-matched organs than those recipients who did not have PVR concerns in terms of either weight $(P=.83)$, BSA $(P=.84)$, or age $(P=.90)$.

\section{The RCM Group}

The RCM group was particularly at risk of RVF. All 8 patients with RCM that developed into RVF had preoperative cardiac catheter: median TPG was 15 (IQR 12, 17) and PVRI was 4.7 (IQR 4.4, 5.0).

\section{Regression Models: Variables of Interest and RVF}

Multiple logistic regression analyses indicated that elevated PVR (odds ratio [OR] 12.30, 95\% confidence interval $[\mathrm{CI}] 2.73,55.32 ; P=.001)$, primary diagnosis (RCM: OR 9.21, 95\% CI 2.07, 41.12; $P=.004$ ), and CHD (OR $4.07,95 \%$ CI $1.36,12.19 ; P=.012$ ) were independently associated with RVF (Table 2). The duration of heart failure, linked to RVF on univariate analysis, became nonsignificant with $P=.65$.

\section{Postoperative Management of RVF}

All patients with RVF received conventional ventilation with alkalinization and avoidance of respiratory acidosis, a phosphodiesterase inhibitor (milrinone) infusion, and inotropic support (Table 3). iNO was started in 28 
TABLE 2. Univariate and multiple logistic regression analyses of risk factors for RVF

\begin{tabular}{|c|c|c|c|c|c|c|}
\hline \multirow[b]{2}{*}{ Factor } & \multicolumn{3}{|c|}{ Univariate } & \multicolumn{3}{|c|}{ Multiple } \\
\hline & $\begin{array}{l}\text { Odds } \\
\text { ratio }\end{array}$ & $\begin{array}{c}95 \% \\
\text { CI }\end{array}$ & $\begin{array}{c}P \\
\text { value }\end{array}$ & $\begin{array}{l}\text { Odds } \\
\text { ratio }\end{array}$ & $\begin{array}{c}95 \% \\
\text { CI }\end{array}$ & $\begin{array}{c}P \\
\text { value }\end{array}$ \\
\hline $\begin{array}{l}\text { Heart failure } \\
\quad(\text { per } 6 \mathrm{mo})\end{array}$ & 1.49 & $1.08,2.06$ & .015 & 1.10 & $0.74,1.65$ & .65 \\
\hline $\begin{array}{r}\text { Pretransplant } \\
\text { ventilation }\end{array}$ & 0.49 & $0.20,1.20$ & .12 & N/A & & \\
\hline Pretransplant ECLS & 1.02 & $0.39,2.69$ & .96 & N/A & & \\
\hline RCM vs DCM & 10.86 & $2.88,41.00$ & $<.001$ & 9.21 & $2.07,41.12$ & .004 \\
\hline CHD vs DCM & 3.73 & $1.45,9.71$ & .007 & 4.07 & $1.36,12.19$ & .012 \\
\hline $\begin{array}{l}\text { Pretransplant } \\
\text { elevated PVR }\end{array}$ & 11.62 & $2.92,46.27$ & .001 & 12.30 & $2.73,55.32$ & .001 \\
\hline $\begin{array}{l}\text { Total ischemic time } \\
\text { (per hour) }\end{array}$ & 1.21 & $0.82,1.79$ & .32 & N/A & & \\
\hline
\end{tabular}

$(84 \%)$ and continued for a median 91 (IQR 29, 135) hours. In 11 patients, iNO was started in the operating theater when RVF was recognized immediately coming off bypass. Prostacyclin infusion was started in $13(40 \%)$ at a median of 3 (IQR 2, 4) days after transplant and continued for a median duration of 10 (IQR 4, 18) days. Renal support in the form of continuous venovenous hemofiltration was required in $13(40 \%)$ of those with RVF. Mechanical support was needed in $10(31 \%)$ : 6 patients on ECMO and 4 with right ventricular assist devices ( 2 converted to ECMO due to pulmonary failure). The trigger for mechanical support was worsening clinical condition despite maximizing conventional RVF treatment; 5 were started on mechanical support in the operating theater and in 5 ( 3 on the day of transplant and 2 on day 2 of transplant) cases, mechanical support was initiated in the cardiac intensive care unit. The median number of mechanical ventilation days for patients with RVF was 11.2 (IQR 3.7, 18) and the median length of ICU stay was 12.8 (IQR 7, 22) days. Both parameters were significantly elevated in the RVF group $(P=.003$ and .006 , respectively, shown in Table 1), reflecting the greatly increased morbidity from RVF.

\section{Survival Outcome}

Survival outcomes are shown in Table 4 and Figures 1 and 2. Over a median follow-up period of 3.7 (IQR 2.1, 5.3) years, there were 14 deaths $(10.8 \%)$. Early postprocedural survival for the cohort was $122 / 129(94.6 \%)$, and actuarial survival at 5 years was $86.1 \%$ (95\% CI 76.6, $91.9 \%$ ). Seven were postprocedural deaths: 4 from RVF and 7 were late deaths at a median interval of 2.1 (IQR 1.8, 3.5) years from the transplantation. A univariate Cox model including 478.1 years of patient follow-up time indicated weak evidence that RVF (hazard ratio [HR] 2.66, 95\% CI 0.91,
TABLE 3. Overview of treatment for RVF in the 3 primary diagnostic categories

\begin{tabular}{lccc}
\hline $\begin{array}{c}\text { Treatment } \\
\text { of RVF }\end{array}$ & DCM $(\mathbf{n}=\mathbf{1 4})$ & RCM $(\mathbf{n}=\mathbf{8})$ & CHD $(\mathbf{n}=\mathbf{1 1})$ \\
\hline $\begin{array}{l}\text { Inhaled nitric } \\
\text { oxide }\end{array}$ & $12 / 14(85 \%)$ & $6 / 8(75 \%)$ & $10 / 11(90 \%)$ \\
Prostacyclin & $2 / 14(14 \%)$ & $7 / 8(87.5 \%)$ & $4 / 11(36 \%)$ \\
Mechanical & $3 / 14(21 \%)$ & $4 / 8(50 \%)$ & $3 / 11(27 \%)$ \\
$\quad$ support & 3 ECMO & 1 ECMO, $1 \mathrm{RVAD}$, & 2 ECMO, \\
& & $2 \mathrm{RVAD} / \mathrm{ECMO}$ & $1 \mathrm{RVAD}$ \\
& $3 / 14(21 \%)$ & $5 / 8(62.5 \%)$ & $5 / 11(45 \%)$ \\
Hemofiltration & 0 & $1 / 8(12.5 \%)$ & 0 \\
Atrial septostomy & 0 & $1 / 8(12.5 \%)$ & $1 / 11(9 \%)$ \\
Retransplantation & 8.2 & 15.7 & 6.6 \\
Days ventilated & $(3.8,19.5)$ & $(7.0,51.3)$ & $(3.9,14.1)$ \\
& 9.3 & 17.6 & 12.8 \\
Days in intensive & $(6.3,20.8)$ & $(11.6,42.3)$ & $(6.9,17.4)$ \\
$\quad$ care & $14 / 14(100 \%)$ & $6 / 8(75 \%)$ & $9 / 11(82 \%)$ \\
Survival to & & & \\
$\quad$ hospital discharge & & & \\
\hline
\end{tabular}

$C H D$, Congenital heart disease; $D C M$, dilated cardiomyopathy; $E C M O$, extracorporeal membrane oxygenation; $R C M$, restrictive cardiomyopathy; $R V A D$, right ventricular assist device; $R V F$, right ventricular failure. Results are median (interquartile range) or $\mathrm{n}(\%)$.

$7.71 ; P=.07)$ and RCM (HR 3.46, 95\% CI 0.90, 13.24; $P=.07)$ were associated with greater mortality risk. There was strong evidence that pretransplant elevated PVR was a related to mortality (HR 6.37, 95\% CI 2.12, 19.05; $P=.001)$. A Cox multiple regression model including primary diagnosis, RVF, and elevated PVR indicated that only PVR was an independent predictor of long-term outcome (HR 5.45, 95\% CI 1.36, 21.97; $P=.017$ ), and both RVF and RCM were nonsignificant (Figures 1 and 2).

\section{DISCUSSION \\ Our Results Summary}

In this single-center retrospective study over a 7-year period, we found that acute RVF developed in one-fourth of the carefully selected pediatric heart transplant recipients in the immediate postoperative period. Surprisingly, the majority $(24 / 33 ; 72 \%)$ of children with RVF were judged to have acceptable PVR on pretransplant assessment. As well as pretransplant elevated PVR, the primary diagnosis (RCM then CHD) was significantly linked to the evolution of RVF. This may reflect the difficulties assessing PVR in certain children with end-stage heart failure. The RVF group experienced greater early morbidity and required aggressive intensive care support. Although some early deaths were attributed to RVF, survival analysis indicated the only important predictor of long-term outcome was a pretransplant elevation in PVR.

\section{How Do Our Results Compare With Other Studies?}

Huang and colleagues ${ }^{12}$ studied risk factors for primary graft failure in 165 pediatric transplant recipients over 
TABLE 4. Univariate and multiple Cox regression analyses of risk factors for death

\begin{tabular}{|c|c|c|c|c|c|c|}
\hline \multirow[b]{2}{*}{ Factor } & \multicolumn{3}{|c|}{ Univariate } & \multicolumn{3}{|c|}{ Multiple } \\
\hline & $\begin{array}{c}\text { Hazard } \\
\text { ratio }\end{array}$ & $\begin{array}{c}95 \% \\
\text { CI }\end{array}$ & $\begin{array}{c}P \\
\text { value }\end{array}$ & $\begin{array}{c}\text { Hazard } \\
\text { ratio }\end{array}$ & $\begin{array}{c}95 \% \\
\text { CI }\end{array}$ & $\begin{array}{c}P \\
\text { value }\end{array}$ \\
\hline RVF & 2.66 & $0.91,7.71$ & .07 & 1.03 & $0.25,4.30$ & .97 \\
\hline Pretransplant ECLS & 2.09 & $0.70,6.26$ & .19 & N/A & & \\
\hline $\mathrm{RCM}$ & 3.46 & $0.90,13.24$ & .07 & 2.23 & $0.51,9.87$ & .29 \\
\hline CHD & 1.36 & $0.36,5.14$ & .65 & 1.39 & $0.36,5.41$ & .63 \\
\hline Elevated PVR & 6.37 & $2.12,19.05$ & .001 & 5.45 & $1.36,21.97$ & .017 \\
\hline
\end{tabular}

a period of 15 years and reported occurrence of isolated RVF in $9 \%$. This study identified pretransplant ventilator support and PVRI as significant risk factors for the development of RVF. The higher incidence of RVF in our cohort may reflect differences in case mix-for example, more patients with RCM or single-ventricle palliation. The use of ECMO for RVF was greater in the cohort of Huang and colleagues ${ }^{12}$ than ours, perhaps reflecting the more recent use of iNO and other conventional modalities in our patients. Fukushima and associates ${ }^{10}$ studied risk factors for graft failure in pediatric heart transplantation and found that the mortality rate from pulmonary hypertension in infants was significantly lower than that in older children despite the overall mortality rate being higher in the infants. This study concluded that older patients experienced greater PVR-related mortality after heart transplantation, especially patients with CHD who received a graft preserved more than 6 hours; however, long-term follow-up was not described. Bando and coworkers $^{23}$ assessed the influence of preoperative factors on outcome after pediatric heart transplant in 2 different eras over a 10 -year period. This study, like ours, found that elevated TPG was the only independent risk factor for death overall, in both early and late postoperative periods. In a study by Hsu and colleauges ${ }^{24}$ from the early 1990s, a pretransplant diagnosis of CHD increased the likelihood of graft failure, possibly related to the need for longer operation, higher risk of bleeding, and difficult implantation.

\section{The Role of Elevated PVR}

Elevated PVR is a known risk factor for death following transplantation, ${ }^{25}$ and RVF in the context of increased PVR has been described in earlier series. ${ }^{23,26-28}$ When considering a patient with reactive but elevated PVR for transplantation, the expectation is that resistance will fall after transplantation. Bhatia and colleagues ${ }^{29}$ evaluated posttransplant resolution of pulmonary hypertension and reported a continual decrease in hemodynamic indices throughout the first year with $80 \%$ of patients demonstrating normal PVR at 1 year. In a study of patients transplanted for RCM, Kimberling and associates ${ }^{17}$ reported that the

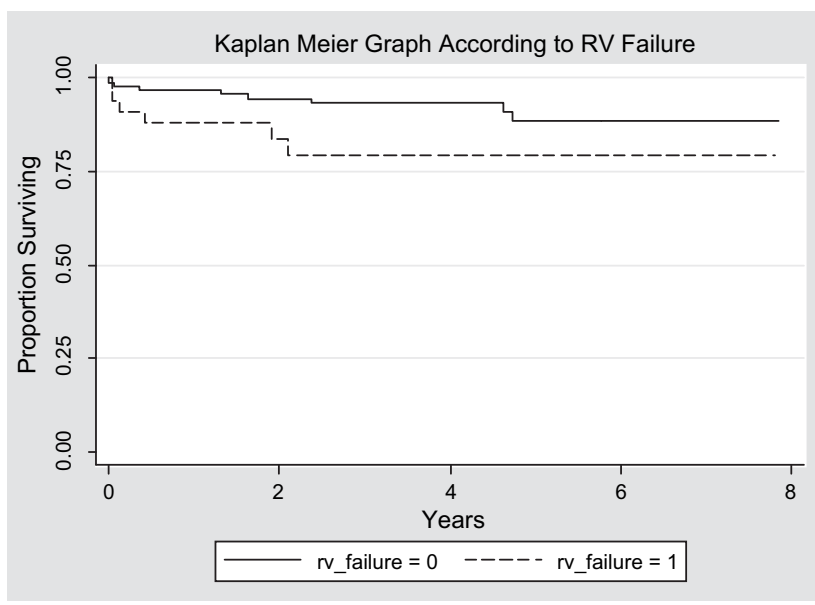

FIGURE 1. Kaplan-Meier survival statistics for patients divided by the presence of right ventricular $(R V)$ failure. The difference between the 2 groups was not statistically significant using Cox regression.

posttransplant PVR had normalized, and similar findings were reported by Gajarski and coworkers. ${ }^{30}$

Accurate assessment of PVR prior to transplantation and the related decision making present particular challenge in the pediatric heart failure population. There is wide variation in the acceptance criteria for heart transplant listing with respect to indices of PVR between different centers, though several investigators have reported that posttransplant RVF is unlikely if the PVRI is less than or equal to $4 \mathrm{WU} \cdot \mathrm{m}^{2}$ with vasodilator therapy ${ }^{17,21,23,30}$; however, some maintain that a pretransplant PVRI less than $8 \mathrm{WU} \cdot \mathrm{m}^{2}$ is acceptable. ${ }^{31}$ The reactivity of the pulmonary vascular bed is considered to be more important than the absolute resistance in determining suitability. ${ }^{30,32}$

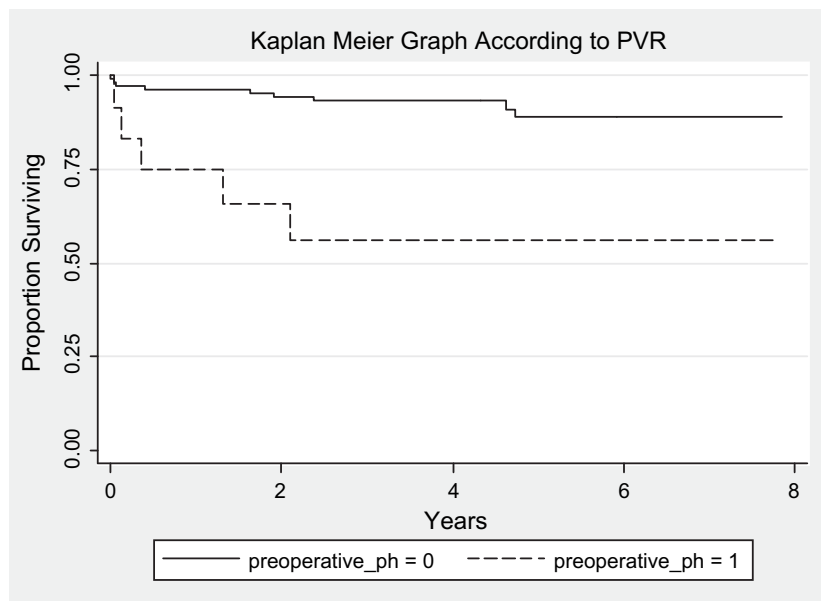

FIGURE 2. Kaplan-Meier survival statistics for patients divided by the presence of pretransplant elevated pulmonary vascular resistance $(P V R)$. The difference between the 2 groups was statistically significant using Cox regression. 
Variation in PVR has been described in individual candidates waiting for heart transplantation, making the interpretation of findings more difficult. ${ }^{33}$ In the context of newer pulmonary vasodilators and the use of mechanical assist devices to decrease PVR, the definition of true, fixed elevated PVR has become more uncertain. ${ }^{21}$ Assessment of PVR in the patient with single-ventricle palliation, those with complex CHD, and those with long-standing DCM and either very poor function or mechanical assistance may be extremely difficult, and at times accurate determination may be impossible ${ }^{3}$ and carries significant morbidity and mortality. In light of this potential risk, our institutional policy is to perform cardiac catheterization in all patients with a primary diagnosis of RCM and in those with CHD. We do not catheterize those with DCM unless there is disproportionately elevated pulmonary artery pressure. In our series, all 12/12 with RCM and 25/27 with CHD had pretransplant catheter data and only 7/90 DCM were catheterized.

Recent reports on the benefit of sildenafil in peritransplantation phase ${ }^{34}$ and use of ventricular assist devices ${ }^{35}$ in reducing pretransplant elevated PVR need to be supported with studies on larger numbers of patients. However, there are major resource implications, and risks of ventricular assist device support are not inconsequential.

\section{Consideration of Other Factors as Causes of RVF}

We considered the potential effects of donor-related myocardial strain: organ preservation and ischemia-reperfusion injury, cardiopulmonary bypass-induced elevated PVR, and postoperative pulmonary dysfunction, which can contribute or result in acute right heart dysfunction. Prolonged ischemic time especially in combination with pretransplant elevated PVR has been implicated in RVF in adult $^{36}$ though not in pediatric studies. ${ }^{37,38}$ However, in our cohort, neither graft ischemic time nor other donor factors appeared to be related to RVF. The only marginal finding was a borderline suggestion that greater donor to recipient BSA ratio may have been linked with RVF, but this finding was not conclusive. We checked whether there was any evidence for selection of more oversized grafts in patients deemed to be at risk of RVF in terms of high PVR, and we found no indication that this was the case. All donor to recipient weight ratios were within acceptable range (neither undersized nor oversized, both of which are implicated in primary graft failure) ${ }^{5,12}$ There is an intuitive belief that oversized allografts may support the right ventricle to generate sufficient pressures and thus compete with the raised PVR. However, there is no clear evidence that oversizing is beneficial. On the contrary, there is evidence that large donors may have a negative impact on survival in this group of patients from the study published by Costanzo-Nordin and associates, ${ }^{29}$ who found that when percent donor weight-recipient ideal weight mismatch was used as a continuous variable, donor heart oversizing was negatively related to survival, independent of preoperative TPG values $(P<.05) .^{39}$

We considered the effect of pretransplant mechanical ventilation and mechanical support, finding neither was associated with RVF; this is in contrast to the study by Huang and colleagues. $^{12}$ The majority $(24 / 27 ; 88.9 \%)$ of patients who were bridged to transplant in our cohort had a primary diagnosis of DCM, which was the group at lowest risk of RVF. Prolonged heart failure was associated with increased risk of RVF on univariate analysis, but this was most likely linked to the more important predictor, elevated PVR, and consequently became nonsignificant in the multiple regression analyses.

\section{Management of Acute RVF}

Vasodilator therapy is required in the management of acute RVF, and the selectivity of iNO to the pulmonary vasculature makes this the ideal agent; this was used in $84 \%$ of our cohort. Comparisons with sodium nitroprusside, prostacyclin, and prostaglandin demonstrated that iNO provided similar pulmonary vasodilatation to prostacyclin but, importantly, iNO was the only vasodilator that was selective following transplantation. ${ }^{40-42}$ Early use of iNO before termination of cardiopulmonary bypass has been described by Ardehali and coworkers ${ }^{43}$ in 16 adults post-heart transplantation; they found that early iNO use reduced PVR and improved RV stroke volume and improved survival. ${ }^{43}$ In a retrospective study of pediatric heart transplant recipients, Bauer and colleagues ${ }^{44}$ showed that prophylactic use of intravenous vasodilator/iNO and phosphodiesterase inhibitor, started at weaning of cardiopulmonary bypass and continued until reduction of PVR and/or adaptation of RV to an elevated afterload, prevented RVF. A similar preventative anesthetic and perioperative strategy has been described by Schindler and colleagues ${ }^{45}$ in their study of 90 transplants over a 13-year period. Use of mechanical support for graft failure $^{12,46}$ and improved survival are well described. The survival was $60 \%$ in those supported on ECMO in our cohort, which is similar to other series. ${ }^{12}$ In subsequent patients after this series, we have elected to create a small atrial communication in the donor heart in those felt to be at greatest risk of RVF. The result of this strategy on outcome will need to be analyzed over time.

\section{Outcome}

The outcome for this pediatric heart transplant cohort is favorable in comparison with other pediatric series, with a postprocedural survival rate of $94.6 \%$ and an actuarial 5 -year survival rate of $86.1 \%$. The role of pretransplant PVR in determining adverse long-term outcome is well recognized, and the multiple regression analyses indicated that this clearly remains of key importance. We have noted that acute RVF posttransplant is a major source of postoperative morbidity and that this contributes to early mortality, but the 
majority of deaths occurred in the worst group, which had the highest level of PVR. The survival analysis ultimately indicated that with careful and aggressive postoperative management, a large proportion of RVF cases responds to treatment and recover.

We have looked at limited factors relating to RV failure and acknowledge that many other issues may be implicated in determining long-term outcome such as compliance, rejection episodes, and cytomegalovirus infection, to mention a few, which we have not analyzed. Also, with the lack of effect of RVF on long-term outcome, there is the possibility of type II error. However, we found that reactive pretransplant PVR, though it can be manipulated and may decrease with time posttransplant, nevertheless still remains significant enough to have an impact on long-term outcome. Similar findings have been reported by Butler and colleagues ${ }^{47}$ in 182 adult recipients with an average follow-up period of $42 \pm 28$ months that pretransplant pulmonary hypertension, even when reversible to a PVR of $\leq 2.5$ $\mathrm{WU}$, is associated with a higher mortality posttransplant. It is possible that some posttransplant right ventricular characteristics, such as presence of tricuspid regurgitation and diastolic dysfunction, may develop over time, which may explain why elevated PVR remains an independent risk factor for later mortality.

\section{Limitations}

This is a retrospective, single-center study and therefore will be subject to local case mix and practice patterns. This is of particular relevance when considering the pretransplant assessment of PVR and the criteria for transplant listing, which are known to vary from one center to another. Certain patient subgroups analyzed are small, and consequently, the reported confidence intervals are wide. The cohort spans a period of 7 years, over which there were some practice changes, as familiarity grew with the early use of iNO and other conventional supportive treatment for acute RVF after transplant.

\section{CONCLUSIONS}

In this pediatric cardiac transplant cohort, acute RVF developed in one-fourth of recipients-in particular, recipients with RCM, CHD, and elevated PVR. Despite careful recipient selection and perioperative care, avoidance of RVF was not always possible. A protocol for preemptive management of RVF appears to be critical in high-risk groups. Aggressive management of RVF with iNO beginning in the operating room, early prostacyclin therapy, and use of ECMO and $\mathrm{RV}$ afterload reduction are recommended, and we conclude that this may minimize early mortality. Further research is required to reliably identify those pediatric recipients who will experience transient RVF after heart transplantation. Pretransplant elevation of PVR, albeit reactive, remains the single most important determinant of long-term outcome.
We acknowledge the statistical support provided by Ms Deborah Ridout, MSc, Paediatric Epidemiology \& Biostatistics, UCL Institute of Child Health, 30 Guilford Street, London WC1N 1EH, UK.

\section{References}

1. Chen JM, Levin HR, Michler RE, Prusmack CJ, Rose EA, Aaronson KD. Reevaluating the significance of pulmonary hypertension before cardiac transplantation: determination of optimal thresholds and quantification of the effect of reversibility on perioperative mortality. J Thorac Cardiovasc Surg. 1997; 114:627-34.

2. Costard-Jackle A, Fowler MB. Influence of preoperative pulmonary artery pressure on mortality after heart transplantation: testing of potential reversibility of pulmonary hypertension with nitroprusside is useful in defining a high risk group. J Am Coll Cardiol. 1992;19:48-54.

3. Trento A, Griffith BP, Fricker FJ, Kormos RL, Armitage J, Hardesty RL. Lessons learned in pediatric heart transplantation. Ann Thorac Surg. 1989;48:617-22; discussion 622-3.

4. Hehrlein FW, Netz H, Moosdorf R, Dapper F, Scheld HH, Bauer J, et al. Pediatric heart transplantation for congenital heart disease and cardiomyopathy. Ann Thorac Surg. 1991;52:112-7.

5. Tamisier D, Vouhe P, Le Bidois J, Mauriat P, Khoury W, Leca F. Donor-recipient size matching in pediatric heart transplantation: a word of caution about small grafts. J Heart Lung Transplant. 1996;15:190-5

6. Boucek RJ Jr, Boucek MM. Pediatric heart transplantation. Curr Opin Pediatr. 2002;14:611-9.

7. Coskun O, Parsa A, Coskun T, El Arousy M, Blanz U, Von Knyphausen E, et al. Outcome of heart transplantation in pediatric recipients: experience in 128 patients. ASAIO J. 2007;53:107-10.

8. Morales DL, Dreyer WJ, Denfield SW, Heinle JS, McKenzie ED, Graves DE, et al. Over two decades of pediatric heart transplantation: how has survival changed? J Thorac Cardiovasc Surg. 2007;133:632-9.

9. Sweet SC, Wong HH, Webber SA, Horslen S, Guidinger MK, Fine RN, et al. Pediatric transplantation in the United States, 1995-2004. Am J Transplant. 2006;6(5 Pt 2):1132-52.

10. Fukushima N, Gundry SR, Razzouk AJ, Bailey LL. Risk factors for graft failure associated with pulmonary hypertension after pediatric heart transplantation. J Thorac Cardiovasc Surg. 1994;107:985-9.

11. George I, Xydas S, Topkara VK, Ferdinando C, Barnwell EC, Gableman L, et al. Clinical indication for use and outcomes after inhaled nitric oxide therapy. Ann Thorac Surg. 2006;82:2161-9.

12. Huang J, Trinkaus K, Huddleston CB, Mendeloff EN, Spray TL, Canter CE. Risk factors for primary graft failure after pediatric cardiac transplantation: importance of recipient and donor characteristics. J Heart Lung Transplant. 2004;23:716-22.

13. Hosenpud JD, Bennett LE, Keck BM, Boucek MM, Novick RJ. The Registry of the International Society for Heart and Lung Transplantation: seventeenth official report-2000. J Heart Lung Transplant. 2000;19:909-31.

14. Butler J, Chomsky DB, Wilson JR. Pulmonary hypertension and exercise intolerance in patients with heart failure. J Am Coll Cardiol. 1999;34:1802-6.

15. Adatia I, Perry S, Landzberg M, Moore P, Thompson JE, Wessel DL. Inhaled nitric oxide and hemodynamic evaluation of patients with pulmonary hypertension before transplantation. J Am Coll Cardiol. 1995;25:1656-64.

16. Fenton MJ, Chubb H, McMahon AM, Rees P, Elliott MJ, Burch M. Heart and heart-lung transplantation for idiopathic restrictive cardiomyopathy in children. Heart. 2006;92:85-9.

17. Kimberling MT, Balzer DT, Hirsch R, Mendeloff E, Huddleston CB, Canter CE. Cardiac transplantation for pediatric restrictive cardiomyopathy: presentation, evaluation, and short-term outcome. J Heart Lung Transplant. 2002;21:455-9.

18. Weller RJ, Weintraub R, Addonizio LJ, Chrisant MR, Gersony WM, Hsu DT. Outcome of idiopathic restrictive cardiomyopathy in children. Am J Cardiol. 2002;90:501-6.

19. Mitchell MB, Campbell DN, Boucek MM. Heart transplantation for the failing Fontan circulation. Semin Thorac Cardiovasc Surg Pediatr Card Surg Annu. 2004; 7:56-64.

20. Bernstein D, Naftel D, Chin C, Addonizio LJ, Gamberg P, Blume ED, et al. Outcome of listing for cardiac transplantation for failed Fontan: a multi-institutional study. Circulation. 2006;114:273-80.

21. Canter CE, Shaddy RE, Bernstein D, Hsu DT, Chrisant MR, Kirklin JK, et al. Indications for heart transplantation in pediatric heart disease: a scientific statement from the American Heart Association Council on Cardiovascular Disease in the Young; the Councils on Clinical Cardiology, Cardiovascular 
Nursing, and Cardiovascular Surgery and Anesthesia; and the Quality of Care and Outcomes Research Interdisciplinary Working Group. Circulation. 2007; 115:658-76.

22. Galie N, Torbicki A, Barst R, Dartevelle P, Haworth S, Higenbottam T, et al. Guidelines on diagnosis and treatment of pulmonary arterial hypertension. The Task Force on Diagnosis and Treatment of Pulmonary Arterial Hypertension of the European Society of Cardiology. Eur Heart J. 2004;25:2243-78.

23. Bando K, Konishi H, Komatsu K, Fricker FJ, del Nido PJ, Francalancia NA, et al. Improved survival following pediatric cardiac transplantation in high-risk patients. Circulation. 1993;88(5 Pt 2):II218-23.

24. Hsu DT, Quaegebeur JM, Michler RE, Smith CR, Rose EA, Kichuk MR, et al. Heart transplantation in children with congenital heart disease. J Am Coll Cardiol. 1995;26:743-9.

25. Kirklin JK, Naftel DC, McGiffin DC, McVay RF, Blackstone EH, Karp RB. Analysis of morbid events and risk factors for death after cardiac transplantation. J Am Coll Cardiol. 1988;11:917-24.

26. Murali S, Kormos RL, Uretsky BF, Schechter D, Reddy PS, Denys BG, et al. Preoperative pulmonary hemodynamics and early mortality after orthotopic cardiac transplantation: the Pittsburgh experience. Am Heart J. 1993;126: 896-904.

27. Bourge RC, Kirklin JK, Naftel DC, White C, Mason DA, Epstein AE. Analysis and predictors of pulmonary vascular resistance after cardiac transplantation. J Thorac Cardiovasc Surg. 1991;101:432-44; discussion 444-5.

28. Vouhe PR, Tamisier D, Leca F, Le Bidois J, Khoury W, Mauriat P, et al. Heart transplantation in children: risk factors of early and late mortality. Eur J Cardiothorac Surg. 1991;5:176-80; discussion 181-2.

29. Bhatia SJ, Kirshenbaum JM, Shemin RJ, Cohn LH, Collins JJ, Di Sesa VJ, et al. Time course of resolution of pulmonary hypertension and right ventricular remodeling after orthotopic cardiac transplantation. Circulation. 1987;76:819-26.

30. Gajarski RJ, Towbin JA, Bricker JT, Radovancevic B, Frazier OH, Price JK, et al. Intermediate follow-up of pediatric heart transplant recipients with elevated pulmonary vascular resistance index. J Am Coll Cardiol. 1994;23:1682-7.

31. Webber SA. The current state of, and future prospects for, cardiac transplantation in children. Cardiol Young. 2003;13:64-83.

32. Zales VR, Pahl E, Backer CL, Crawford S, Mavroudis C, Benson DW Jr. Pharmacologic reduction of pretransplantation pulmonary vascular resistance predicts outcome after pediatric heart transplantation. J Heart Lung Transplant. 1993;12(6 Pt 1):965-72; discussion 972-3.

33. Boffa GM, Razzolini R, Grassi G, Basso C, Ramondo A, Isabella G, et al. Pulmonary vascular resistance variation over time in candidates for heart transplantation. Am J Cardiol. 1994;73:414-5.
34. Maruszewski M, Zakliczynski M, Przybylski R, Kucewicz-Czech E, Zembala M. Use of sildenafil in heart transplant recipients with pulmonary hypertension may prevent right heart failure. Transplant Proc. 2007;39:2850-2.

35. Gandhi SK, Grady RM, Huddleston CB, Balzer DT, Canter CE. Beyond Berlin heart transplantation in the "untransplantable.". J Thorac Cardiovasc Surg. 2008;136:529-31.

36. Marasco SF, Esmore DS, Richardson M, Bailey M, Negri J, Rowland M, et al. Prolonged cardiac allograft ischemic time-no impact on long-term survival but at what cost? Clin Transplant. 2007;21:321-9.

37. Morgan JA, John R, Park Y, Addonizio LJ, Oz MC, Edwards NM, et al Successful outcome with extended allograft ischemic time in pediatric heart transplantation. J Heart Lung Transplant. 2005;24:58-62.

38. Scheule AM, Zimmerman GJ, Johnston JK, Razzouk AJ, Gundry SR, Bailey LL. Duration of graft cold ischemia does not affect outcomes in pediatric heart transplant recipients. Circulation. 2002;106(12 Suppl. 1):I163-7.

39. Costanzo-Nordin MR, Liao YL, Grusk BB, O'Sullivan EJ, Cooper RS Johnson MR, et al. Oversizing of donor hearts: beneficial or detrimental? J Heart Lung Transplant. 1991;10(5 Pt 1):717-30.

40. Kieler-Jensen N, Lundin S, Ricksten SE. Vasodilator therapy after heart transplantation: effects of inhaled nitric oxide and intravenous prostacyclin, prostaglandin E1, and sodium nitroprusside. J Heart Lung Transplant. 1995;14:436-43.

41. Williams TJ, Salamonsen RF, Snell G, Kaye D, Esmore DS. Preliminary experience with inhaled nitric oxide for acute pulmonary hypertension after heart transplantation. J Heart Lung Transplant. 1995;14:419-23.

42. Auler Junior JO, Carmona MJ, Bocchi EA, Bacal F, Fiorelli AI, Stolf NA, et al. Low doses of inhaled nitric oxide in heart transplant recipients. J Heart Lung Transplant. 1996;15:443-50.

43. Ardehali A, Hughes K, Sadeghi A, Esmailian F, Marelli D, Moriguchi J, et al Inhaled nitric oxide for pulmonary hypertension after heart transplantation. Transplantation. 2001;72:638-41.

44. Bauer J, Dapper F, Demirakca S, Knothe C, Thul J, Hagel KJ. Perioperative management of pulmonary hypertension after heart transplantation in childhood J Heart Lung Transplant. 1997;16:1238-47.

45. Schindler E, Muller M, Akinturk H, Valeske K, Bauer J, Zickmann B, et al Perioperative management in pediatric heart transplantation from 1988 to 2001 : anesthetic experience in a single center. Pediatr Transplant. 2004;8:237-42.

46. Shaddy RE. Pulmonary hypertension in pediatric heart transplantation. Prog Pediatr Cardiol. 2000;11:131-6.

47. Butler J, Stankewicz MA, Wu J, Chomsky DB, Howser RL, Khadim G, et al. Pretransplant reversible pulmonary hypertension predicts higher risk for mortality after cardiac transplantation. J Heart Lung Transplant. 2005;24:170-7. 